\title{
Assessment of knowledge of Saudi female teenagers \& their mothers regarding management of type I diabetes in the City of Abha
}

\author{
Salwa Ibrahim Beshi ${ }^{1}$, Salma Moawad ${ }^{1}$, Sahar M. Yakout *2 \\ ${ }^{1}$ College of Nursing, King Saud University, Riyadh, Saudi Arabia \\ ${ }^{2}$ Faculty of Nursing, Alexandria University, Alexandria, Egypt
}

Received: December 21, 2016

Accepted: February 6, 2017

Online Published: June 18, 2017

DOI: $10.5430 /$ jnep.v7n9p121

URL: https://doi.org/10.5430/jnep.v7n9p121

\begin{abstract}
Background: Diabetes is predicted to become the seventh leading cause of death in the world by the year 2030. In adolescence self-image is being constructed and diabetes self-care becomes an integral part of daily life. Diabetes management is better when parents remain involved in diabetes care through parental monitoring, a construct frequently measured as parents' overall knowledge of their adolescents' illness management. The main aim of this study was to assess the Knowledge of Saudi Female Teenagers and Their Mothers Regarding Management of type I Diabetes in the Abha.

Methods: The study was carried out in Abha diabetic center. A descriptive, cross-sectional design was used. A non-probability, convenience sample of diabetic Saudi female teenagers (150) and their mothers (150) was required. The researcher prepared a two-sheet questionnaire. The questionnaire was developed from a modified Simplified Diabetes Knowledge Test (DKT) derived from the Revised Diabetes Knowledge Scale, developed by Lloyd (2011) and Fitzgerald (1998), diabetes self-management and the day care diabetes education questionnaire.

Results: More the two third of mothers 30 years old and more, and 46\% their level of education secondary school and more but more than two third were home wife. On the other hand, more than two third of diabetic teenage were their age 16-19 years, and $50 \%$ intermediate school age. The teenager girls and their mothers $(72 \%, 63 \%)$ respectively not participate at any classes related to health education about management. Although only $7 \%$ not have any diabetic complication and statistical analysis show highly significant different between response of mothers and their daughters. In general, it is obvious that most of the mother do not aware or do not carefully follow their daughters in respect of diabetes self-management through diet, physical practice and blood glucose level. Also, mothers' characteristics do not influence on daughters' knowledge level about diabetes self-management. The only factor that has a significant influence on teen females' knowledge was the duration since diagnosed as diabetic.

Conclusions: According to the results of the study, it is concluded that both mother and their daughter had lack of awareness and knowledge in most of aspects of diabetes management so the researcher suggested family-based interventions, implementation of home visit programs and integrated ongoing programs of education, monitoring and support for young people and their families living with diabetes are needed. Further research needs and the paradigm used in the present study should be expanded to include fathers, other family members and friends.
\end{abstract}

Key Words: Knowledge, Type I diabetes, Saudi female teenager, Abha City

*Correspondence: Sahar M. Yakout; Email: szamzam@ksu.edu.sa; Address: Faculty of Nursing, Alexandria University, Alexandria, Egypt. 


\section{INTRODUCTION}

Type I diabetes, known as juvenile-onset diabetes is a chronic disease whose prevalence is increasing throughout the world It is most often diagnosed in children, adolescents, or young adults. In type I diabetes, beta cells produce little or no insulin. The exact cause of type I diabetes is unknown. Most likely it is an autoimmune disorder. This is a condition that occurs when the immune system mistakenly attacks and destroys healthy body tissue. With type I diabetes, an infection or another trigger causes the body attack the cells in the pancreas that make insulin. Type I diabetes can be passed down through families. It requires continuing medical care and ongoing patient self-management, education and support to prevent acute complications and to reduce the risk of longterm complications. ${ }^{[1]}$ There is good evidence that long-term complications of diabetes can be prevented through proper diabetic control. ${ }^{[2]}$

Individuals with diabetes generally have increased risk of attracting various chronic health problems such as cardiovascular disease, kidney failure, lower limb amputation and blindness cause. Maintenance of blood pressure, blood glucose level, as well as cholesterol levels closer to the normal level may aid in preventing or delaying complications of diabetes. ${ }^{[3,4]}$

Diabetes affect women in many ways. Studies of women with diabetes showed reproductive abnormalities such as delayed menarche and increased incidence of menstrual cycle irregularities and delayed ovulation. ${ }^{[5]}$ The studies found the successful pregnancy was achieved in only $2 \%$ of type 1 diabetic women. The presence of type 1 diabetes in pregnant women has been associated with adverse effects on the fetal outcomes of pregnancy, such as congenital malformations. An increased risk of congenital malformations among diabetic women has been reported. But with the refinement of insulin therapy, improved fertility might be expected. ${ }^{[6]}$

The knowledge of female teenagers and their mothers about the management of type I diabetes is very important, and needs to be stressed on despite the many constrains. Inadequate knowledge is responsible for significant barriers to proper management of diabetes. ${ }^{[7]}$ In essence, type I diabetes are one of the lifelong conditions which invade adolescence lives, as well as that of their parents. Management of which normally imposes huge responsibilities on both, the teenagers and their parents. During the teenage years, management of diabetes is usually challenging for girls. ${ }^{[8]}$ During this period, various psychological, cognitive, and physical changes occur. It leads to this group of people exhibiting neurotic tendencies, emotional instability, in addition to, maladjustments to circumstances and environment. Most specifically, over dependence on the parents, immature or confused sexual identification, creative impulses, restricted instinctive drives, distorted self-perceptions and excessive oral pre-occupation have been said to be a crucial psychological hardship of juvenile diabetes. ${ }^{[9]}$

Several studies found that mothers who have more knowledge have teenagers with even better metabolic control. The mother's knowledge and the influence of the family might enhance the glycemic control, ultimately decreasing chronic and acute complications of diabetes in the teenagers. ${ }^{[7,8,10]}$ Moreover, much research had been carried out on the relationship between compliance and information. ${ }^{[7,11,12]}$ Knowledge on the ailment as well as its treatment is crucial for a patient's compliance, although information on its own is not adequate to encourage required behavioral change for management of the disease. ${ }^{[12]}$

Increase in patient understanding of participation and improvement in diabetes management is linked to much better parental handling with their teenager's diabetes. On the other hand, a majority of families who had teenagers were in position of managing diabetes better, although the burden that was placed on parents may aggravate symptoms of depression. Caring for such adolescents could be accompanied by crucial consequences. Yet, studies on interaction of parent-adolescent in managing the disease showed that the interaction is associated with devotion to treatment and management of diabetes. ${ }^{[13]}$ The pediatric nurse, as a member of the health care team, has a unique role in self-management of diabetic teenagers. She has to educate the teenagers and their mothers about the best of their ability in understanding their condition in such a way that they know enough about their management and self-care in order to change their life style. ${ }^{[14]}$

\subsection{Problem statement}

Diabetes mellitus (DM) is one of the most common metabolic disorders in the Kingdom of Saudi Arabia (KSA). According to some national epidemiological studies, the prevalence of diabetes mellitus is increasing yearly among adolescents in $\mathrm{KSA}^{[15]}$ In the southern region, the prevalence of DM is around $8 \%$ yearly. ${ }^{[16]}$ Also, many of the female teenagers and their mothers are not aware of the severity of the complications that can happen such as: infertility problems, cardiovascular diseases, blindness, and other health problems in addition to death. ${ }^{[6,8]}$

In Abha City, in spite of the fact that diabetes mellitus is increasing every year there is no research found that assess the knowledge of female teenagers and their mothers about type I diabetes management.In this light, type I diabetes require

ISSN 1925-4040 E-ISSN 1925-4059 
persistent medical care, and more importantly, continuing patient support and management education in order to prevent severe complications, while at the same time decreasing long term complication risk. ${ }^{[17]}$ It is for this reason that knowledge of female teenagers and their mothers about diabetic management in Abha city is needed as seen in this paper to help them manage the diabetic condition appropriately with decreased incidence of complications.

\subsection{Aim of the study}

This study aim to assess the level of knowledge of Saudi female teenagers $\&$ their mothers regarding management of type I diabetes in the city of Abha.

\subsection{Research questions}

The research questions of this study are therefore:

(1) What is the level of knowledge of the Saudi diabetic female teenagers regarding the management of type I diabetes in Abha City?

(2) What is the level of knowledge of the mothers of diabetic teenage females regarding type I diabetes in Abha City?

(3) Is there any gap of knowledge between the teenagers and their mothers?

(4) What is the association between the level of knowledge of teenagers and their mothers and selected variables?

\subsection{Operational definitions}

- Assessment: Is the process of gathering information from the people to determine the level of their knowledge.

- Knowledge: Information that the diabetic teenager and her mother have about management of type I diabetes regarding diet, medication, blood test, exercise, foot care, personal hygiene, and hypoglycemia.

- Teenagers: A person aged between 13 and 19 years.

- Type I diabetes: A condition characterized by high blood glucose levels caused by a total lack of insulin. Occurs when the body's immune system attacks the insulin-producing beta cells in the pancreas and destroys them. The pancreas then produces little or no insulin. Type 1 diabetes develops most often in young people but can appear in adults.

\section{METHOD}

\subsection{Research design}

A quantitative approach was adopted in the study with a cross sectional descriptive correlational design was used. As the researcher need to describe the level of knowledge regarding the management of type I diabetes for the mother and

Published by Sciedu Press her daughter is in agreement with polit, and Hungler (2004), who mentioned that the purpose of descriptive studies is to observe, describe and document aspects of a situation or phenomena as it naturally occur without an in depth investigation of why or how it occurs. ${ }^{[18]}$

\subsection{Setting}

This study was conducted in Aseer Diabetic Center in Abha City, as it represents the only center that provides services to diabetic patients, which gives free medical services to people of all ages.

\subsection{Subjects}

A non-probability, convenience sample of 150 diabetic Saudi female teenagers and their mothers (150) were included in the study, which is nearly $10 \%$ of the total number of diabetic teenagers visiting the diabetic center per year. The selected subjects followed the criteria below:

- Saudi female teenagers who have type I diabetes and their mothers.

- Between 13 and 19 years of age.

- Teenagers who are willing to participate in the study.

A subject size calculation tool created by Roasoft incorporate was used to determine the suggested number of participants (90), a number of (300) participants were recommended.

\subsection{Data collection tools}

Data collected through self-administrated questionnaire developed by the researcher after review of the literature. Two questionnaires prepared; one for the teenager diabetic females and the other for their mothers.

The first questionnaire for daughter consisted of two parts:

\section{PART I}

(1) Socio-demographic data, such as age, order in family size, and educational level.

(2) History of menstruation, such as age at menarche, regularity of menstruation, pre and post menstrual syndromes and duration of period.

(3) Daughter's medical history, such as time diagnosed as diabetic, previous hospitalization, follow regular medical checkup, and if she suffers from any complications of Diabetes Mellitus.

\section{PART II}

Knowledge of diabetes management; developed from a modified Simplified Diabetes Knowledge Test (DKT) derived from the Revised Diabetes Knowledge Scale, developed by Lioyd (2011) and Fitzgerald (1998), diabetes selfmanagement and day care diabetes education questionnaire 
$(91,92)$. These includes dietary management, insulin injection, diabetic control, hypo \& hyperglycemia episodes, regularity of daily activities (exercises), blood sugar monitoring, foot care, source of her information and knowledge regarding complications.

The second questionnaire for the mother sonsisted of two parts:

\section{PART I}

(1) Socio-demographic data, such as age, level of education, occupation, and type of family, level of husband's education, job and income.

(2) Family history regarding diabetes and knowledge related to reasons about not say anyone about their daughter's disease, etc.

\section{PART II}

Knowledge about diabetes management (DKT), which include dietary management, insulin injection, diabetic control, hypo and hyperglycemia episodes, regularity of daily activities (exercises), blood sugar monitoring, foot care and knowledge regarding complications.

Scoring system used to determining the knowledge level, answers of question related to knowledge score evaluated by the researcher and allotted score according to the correctness of the answer. The score is 0 for the wrong knowledge and 1 for the right and complete knowledge. The overall knowledge score have been summed up for each case and calculated in a percentage to the total corrected knowledge. Accordingly, knowledge levels identified in three categories namely; Good, Fair and Poor knowledge level.

- Good knowledge: score summation ranges between $66.7 \%$ and $100 \%$.

- Fair knowledge: score summation ranges between $33.4 \%$ and $66.6 \%$.

- Poor knowledge: score summation ranges between 0 and $33.3 \%$.

\subsection{Validity}

Face validity of the questionnaire have been well-established. To establish content validity, the questionnaire was sent to an expert group $(n=6)$ of reviewers that had strong expertise in research and type I diabetes (Three faculty members of King Saud University, two doctors from a primary health care center working with diabetic clients, and one diabetic health educator from Aseer diabetic clients). Minor changes were made to questionnaire based on the comments of the experts. There are other forms of validity that are not mentioned here and should be construct validity (e.g. Factor analysis Both exploratory and Confirmatory).

\subsection{Reliability}

In order to measure the reliability of the instrument the testretest method was used. A pilot study was conducted before to confirm the reliability of the questioners, to test the wording and clarity of the questions, etc. Data were collected from 10 Saudi mothers and their daughters, analysis of reliability was done and the value of Cronbach's alpha coefficient (0.89) which represent of the tool is good reliability. Those mothers and their daughters were not included in the actual study.

\subsection{Administrative approval}

Before the conducting the study, an official letter was sent from King Saud University, college of nursing to the ministry of health, Aseer Health Affairs. Then, an official letter was sent from Aseer Health Affairs to the Aseer Central Hospital. Then, the study was approved by Internal Review Board (IRB) Committee. Then, approval of the Director of Academic Affairs and Research Center at Aseer Central Hospital was obtained before collection of any data.

\subsection{Ethical considerations}

Mothers and their daughters attending the diabetes clinic were told of the purpose of the study and were asked to sign approval consent form if they agreed to participate. They were informed the participation was voluntary and they can withdraw from this study at any time. The consent was taken and their confidentiality was ensured.

\subsection{Data collection procedure}

Data collection covered a period of nearly 8 months from January to August (2015). It was carried out five (5) days per week. Data was collected during scheduled clinic visits.

The average time spent for data collecting was approximately 45 minutes for both daughters and their mothers to complete the questionnaire sheet.

Data collected through self-administrated questionnaire for teen's girls and educated mothers. While those illiterate groups of mothers the interview method was used i.e. the researcher read the question and write the expected mothers' response.

\subsection{Statistical analysis}

Data collected, revised, tabulated, coded, and presented by the researcher. All statistical analysis performed using SPSS statistical package, version 17. Qualitative data expressed as frequencies and percentages. Quantitative data expressed as means and standard deviations.

Statistical significance was set at $p$-value less than .05 , i.e. at $95 \%$ confidence interval. The $\mathrm{P}$-value is the probability

ISSN 1925-4040 E-ISSN 1925-4059 
that an observed difference is due to chance and not a true difference. At $p$-value greater than .05 , this indicates that there is no significant difference between tested variables. At $p$-value equal to/or less than .05 , this indicates a significant difference between tested variables.

Table 1 summarized mother's characteristics concerning age, educational level and employment. Concerning ages, mothers have been distributed among three categories; less than 30 years old; between 30 and 35 years old and older than 35 years old. Most of mothers are older than 35 years old $(65.33 \%)$, Number of young mothers; less than 30 years old and between 30 and 35 years old, are relatively small, together they represent about one third of the subjects. The average age of mothers was 36.6 years old with a standard deviation of 4.9092. Regarding educational level, about one quarter of the mothers either illiterate or just read and write $(23.33 \%)$. One third of the mothers finished primary or intermediate schools $(30.67 \%)$. $46 \%$ of mothers either finished secondary school or university graduated,respectively. In respect of employment, two thirds of the mothers are house wives $(61.33 \%)$, while $(38.67 \%)$ of mothers were employed.

Table 1. Socio-demographic characteristics of of studied subjects type I diabetic teenage females and their mothers (n $=300$ )

\begin{tabular}{|c|c|c|}
\hline \multirow{2}{*}{$\begin{array}{l}\text { Socio-demographic } \\
\text { characteristics of mother }\end{array}$} & \multicolumn{2}{|l|}{$\mathrm{n}=\mathbf{3 0 0}$} \\
\hline & Frequency & Percent (\%) \\
\hline \multicolumn{3}{|l|}{ Mother age } \\
\hline$<30$ years & 24 & 16.00 \\
\hline-35 years & 28 & 18.67 \\
\hline$>35$ years & 98 & 65.33 \\
\hline$\mu \pm \sigma$ & \multicolumn{2}{|l|}{$36.6 \pm 4.9092$} \\
\hline \multicolumn{3}{|l|}{ Mother's educational level } \\
\hline Illiterate & 15 & 10.00 \\
\hline Read and write & 20 & 13.33 \\
\hline Primary & 19 & 12.67 \\
\hline Intermediate & 27 & 18.00 \\
\hline Secondary & 45 & 30.00 \\
\hline University graduate & 24 & 16.00 \\
\hline \multicolumn{3}{|l|}{ Mother's employment } \\
\hline Working & 58 & 38.67 \\
\hline House-wife & 92 & 61.33 \\
\hline \multicolumn{3}{|l|}{ Girls Age } \\
\hline$<16$ years & 54 & 36.00 \\
\hline $16-19$ years & 96 & 64.00 \\
\hline$\mu \pm \sigma$ & \multicolumn{2}{|l|}{$16.42 \pm 1.4448$} \\
\hline \multicolumn{3}{|l|}{ Girls education level } \\
\hline Read and write & 6 & 4.00 \\
\hline Primary & 42 & 28.00 \\
\hline Intermediate & 75 & 50.00 \\
\hline Secondary & 27 & 18.00 \\
\hline \multicolumn{3}{|l|}{ Rank Among Brothers } \\
\hline First & 21 & 14.00 \\
\hline Second & 48 & 32.00 \\
\hline Third & 60 & 40.00 \\
\hline Others & 21 & 14.00 \\
\hline
\end{tabular}

Published by Sciedu Press
As regard the characteristics of type I diabetic teens, their ages are grouped within two age groups; less than 16 years old and between 16 and 19 years old. $64 \%$ of teens are between 16 and 19 years. Regarding educational level, small percent of the teens are just read and write (4\%). Most of the teens are either in primary school or intermediate school $(78 \%)$. Less than one fifth of the teens are in the secondary school (18\%). Concerning the rank of the teens among their families, $14 \%$ of the teens are the oldest among their brothers, $32 \%$ are the second, $40 \%$ are the third.

Table 2 showed the menstrual criteria of studied subjects type I diabetic teens. Among teens $60 \%$ start to menstruate at age between 9 and 12 years old, while $40 \%$ their menarche was at age between 13 and 16 years old. In average the teens started to menstruate at age of about 12.02 years old with a standard deviation of 1.9481. Concerning menstruation regularity, $62 \%$ of the teens have regular menstrual cycle, while $38 \%$ have irregular menstrual cycle. Considerable percentage of type I diabetic teens were suffered from premenstrual cycle problems and pains (66\%). On the other hand, none of them suffered from postmenstrual cycle problems or pains. Period duration varied between 3 days and more than 7 days, $50 \%$ of the teens their period is between 3 and 7 days, while $50 \%$ of the girls their period extended to more than 7 days. In average, the period duration of the teens was about 7 days with a standard deviation of 2.0067 .

Table 2. Menstrual criteria of type I diabetic teenage females

\begin{tabular}{lll}
\hline Menstrual criteria of Type I & $\mathbf{n}=\mathbf{1 5 0}$ & \\
\cline { 2 - 2 } Diabetic Teenage Females & Frequency & Percent (\%) \\
\hline Age at menarche & & \\
9-12 years & 90 & 60.00 \\
13-16 years & 60 & 40.00 \\
$\mu \pm \sigma$ & $12.02 \pm 1.9481$ & \\
Regularity of menstruation & & \\
$\quad$ Regular & 93 & 62.00 \\
Irregular & 57 & 38.00 \\
Symptoms before period & & \\
$\quad$ Yes & 99 & 66.00 \\
$\quad$ No & 51 & 34.00 \\
Symptoms after period & & \\
$\quad$ Yes & 0 & 0 \\
$\quad$ No & 150 & 100.00 \\
Duration of period & & \\
3-7 days & 75 & 50.00 \\
$>7$ days & 75 & 50.00 \\
$\mu \pm \sigma$ & $7 \pm 2.0067$ & \\
\hline
\end{tabular}

Table 3 showed difference in responses between type I diabetic teen females and their mothers concerning diabetes self-management through diet. In respect the follow-up of 
weight, $47.33 \%$ of the mothers noticed weight-loss of their girls, while only $14 \%$ of the teens noticed the weight-loss. Thus, there was a highly statistical significant differences between responses of mothers and their daughters $\left(\chi^{2}=\right.$ 39.1931 with $p<.00001)$. Concerning following diet plan (regime), $16.67 \%$ of mothers' responses indicated that daughters follow diet plan, while $8 \%$ of the teen mentioned that they follow diet plan. These figures showed a highly statistical significant difference $\left(\chi^{2}=5.2101\right.$ with $\left.p<.05\right)$. Regarding number of meals per day, there was a highly significant difference between mothers and their daughter responses. $3.33 \%$ of mothers mentioned that only one meal, $8 \%$ mentioned two meals and $88.67 \%$ mentioned three meals. On the other hand, $6 \%$ of the girls mentioned only one meal, $28 \%$ mentioned two meals and $66 \%$ mentioned three meals.
Statistical analysis showed a highly significant difference where $\chi^{2}=22.7923$ with $p<.00001$. Regarding taking snacks between meals, $90.67 \%$ of mothers mentioned that comparing to $82.00 \%$ of girls who stated that. Statistical analysis showed a significant difference where $\chi^{2}=4.7745$ with $p<.05$. Regarding number of snacks between meals there was a highly significant differences between mothers and their daughter responses, where $\chi^{2}=39.1178$ with $p<$ .00001 . Regarding having meals outside home and frequency of having meals outside home, responses of mothers and their daughters are more or less alike and the statistical analysis didn't show any differences. Responses indicated that most of the type I diabetic teen females used to have meals outside home.

Table 3. Diabetes self-care management through nutrition practices among Studied Subjects from girls and mothers responses

\begin{tabular}{|c|c|c|c|c|c|c|}
\hline \multirow{2}{*}{ Diabetes self-care management } & \multicolumn{2}{|c|}{ Mothers $(\mathrm{N}=150)$} & \multicolumn{2}{|c|}{ Girls $(N=150)$} & \multirow{2}{*}{$\chi^{2}$} & \multirow{2}{*}{$p$} \\
\hline & $\mathbf{n}$ & $\%$ & $\mathbf{n}$ & $\%$ & & \\
\hline \multicolumn{7}{|l|}{ Notice Weight loss } \\
\hline Yes & 71 & 47.33 & 21 & 14.00 & \multirow[t]{2}{*}{39.1931} & \multirow[t]{2}{*}{$3.8 \times 10^{-10 *}$} \\
\hline No & 79 & 52.67 & 79 & 86.00 & & \\
\hline \multicolumn{7}{|l|}{ Follow health eating regime } \\
\hline Yes & 25 & 16.67 & 12 & 8.00 & \multirow[t]{2}{*}{5.2101} & \multirow[t]{2}{*}{.0225} \\
\hline No & 125 & 83.33 & 138 & 92.00 & & \\
\hline \multicolumn{7}{|l|}{ Number of meals per day } \\
\hline One meal & 5 & 3.33 & 9 & 6.00 & \multirow{3}{*}{22.7923} & \multirow{3}{*}{$1.12 \times 10^{-5 *}$} \\
\hline Two meals & 12 & 8.00 & 42 & 28.00 & & \\
\hline Three meals & 133 & 88.67 & 99 & 66.00 & & \\
\hline \multicolumn{7}{|l|}{ Have snacks between meals } \\
\hline Yes & 136 & 90.67 & 123 & 82.00 & \multirow[t]{2}{*}{4.7745} & \multirow[t]{2}{*}{.0289} \\
\hline No & 14 & 9.33 & 27 & 18.00 & & \\
\hline \multicolumn{7}{|l|}{ Number of snacks per day } \\
\hline One snacks & 9 & 6.62 & 36 & 29.27 & \multirow{3}{*}{39.1178} & \multirow{3}{*}{$3.2 \times 10^{-9} *$} \\
\hline Two snacks & 66 & 48.53 & 69 & 56.10 & & \\
\hline Three snacks & 61 & 44.85 & 18 & 14.63 & & \\
\hline \multicolumn{7}{|l|}{ Eat outside home } \\
\hline Yes & 142 & 94.67 & 135 & 90.00 & \multirow[t]{2}{*}{2.3073} & \multirow[t]{2}{*}{.1288} \\
\hline No & 8 & 5.33 & 15 & 10.00 & & \\
\hline \multicolumn{7}{|l|}{ How often eat outside home** } \\
\hline Always & 25 & 17.61 & 18 & 13.33 & \multirow{3}{*}{2.3406} & \multirow{3}{*}{.3103} \\
\hline Sometimes & 99 & 69.72 & 105 & 77.78 & & \\
\hline Rarely & 18 & 12.68 & 12 & 8.89 & & \\
\hline
\end{tabular}

$* p<.05 ; * *$ Selected yes

Table 4 showed difference in responses between type I diabetic teen females and their mothers concerning diabetes self-management through physical exercise practices and insulin taken. In respect to practice physical exercise, $20 \%$ of the mothers mentioned that their daughters practicing phys- ical exercise, while $38 \%$ of the teens mentioned that they regularly practicing physical exercise. Accordingly, there was a highly statistical significant differences between responses of mothers and their daughters $\left(\chi^{2}=11.8018\right.$ with $p<.001)$. Regarding type of physical exercise, mothers 
mentioned jogging, swimming, walking and other types; insulin (76\%). On the other hand, $18 \%$ of the teens men$10 \%, 10 \%, 70 \%$ and $10 \%$ respectively. On the other hand, teens mentioned only jogging and walking as the types of physical exercise they used to practice, $26.62 \%$ and $94.57 \%$ respectively. Therefore, there was a highly significant differences between responses of mothers and their daughter $\left(\chi^{2}=\right.$ 9.0891 with $p<.005)$. Regarding type of insulin taken, mothers mentioned intermediate-acting insulin $(24 \%)$ and mixed tioned intermediate-acting insulin, $68 \%$ mentioned mixed insulin, while $14 \%$ of the girls don't know the type of insulin taken. The responses showed a highly significant difference between mothers and their girls where $\chi^{2}=20.6237$ with $p$ $<.00001$. Regarding number of insulin injections per day, responses of mothers and their daughter highly coincides.

Table 4. Physical exercise practices and insulin taken among studied subjects from girls and mothers responses

\begin{tabular}{|c|c|c|c|c|c|c|}
\hline \multirow{2}{*}{ Physical Exercise Practices and insulin taken } & \multicolumn{2}{|c|}{ Mothers $(\mathrm{N}=150)$} & \multicolumn{2}{|c|}{ Girls $(\mathbf{N}=150)$} & \multirow{2}{*}{$\chi^{2}$} & \multirow{2}{*}{$p$} \\
\hline & $\mathbf{n}$ & $\%$ & $\mathbf{n}$ & $\%$ & & \\
\hline \multicolumn{7}{|l|}{ Practice physical exercise } \\
\hline Yes & 30 & 20.00 & 57 & 38.00 & \multirow[t]{2}{*}{11.8018} & \multirow[t]{2}{*}{$.0006^{*}$} \\
\hline No & 120 & 80.00 & 93 & 62.00 & & \\
\hline \multicolumn{7}{|l|}{ What kind of exercise** } \\
\hline Jogging & 3 & 10.00 & 15 & 26.32 & \multirow{4}{*}{9.0891} & \multirow{4}{*}{$.0026^{*}$} \\
\hline Swimming & 3 & 10.00 & 0 & 0 & & \\
\hline Walking & 21 & 70.00 & 42 & 73.68 & & \\
\hline Other & 3 & 10.00 & 0 & 0 & & \\
\hline \multicolumn{7}{|l|}{ Type of Insulin girl has } \\
\hline Rapid-acting Insulin & 0 & 0 & 0 & 0 & \multirow{4}{*}{20.6237} & \multirow{4}{*}{$3.32 \times 10^{-5 *}$} \\
\hline Intermediate-acting Insulin & 36 & 24.00 & 27 & 18.00 & & \\
\hline Mixed Insulin & 114 & 76.00 & 102 & 68.00 & & \\
\hline Don’t know & 0 & 10.00 & 21 & 14.00 & & \\
\hline \multicolumn{7}{|l|}{ How many Insulin injections per day? } \\
\hline Once a day & 0 & 0 & 0 & 0 & \multirow{4}{*}{0.000} & \multirow{4}{*}{1.00} \\
\hline Twice a day & 39 & 26.00 & 39 & 26.00 & & \\
\hline Three times a day & 93 & 62.00 & 93 & 62.00 & & \\
\hline Others & 18 & 12.00 & 18 & 12.00 & & \\
\hline
\end{tabular}

$* p<.05 ; * *$ Selected yes

Table 5 showed the difference in responses between type I diabetic teen females and their mothers concerning diabetes self-management through measuring and follow-up glucose level practice. Concerning measuring glucose level practice at home, $26.67 \%$ of the mothers mentioned that their daughters practicing measure glucose level at home, while $38 \%$ of the teens mentioned that they regularly check their glucose level at home. therefore, there was a statistical significant differences between responses of mothers and their daughters $\left(\chi^{2}=4.4030\right.$ with $\left.p<.05\right)$. Regarding type of test girls used, mothers mentioned glucometer as the only instrument girls used. On the other hand, $84.21 \%$ of teens mentioned glucometer, while 15.79 used urine strips. Therefore, there was a significant differences between responses of mothers and their daughter $\left(\chi^{2}=5.2103\right.$ with $\left.p<.05\right)$. Regarding regularity of measuring glucose level, there was no statistical significant difference between mothers and their daughters' responses. Even for time of measuring glucose level, type of insulin taken, there was no statistical significant difference between mothers and their daughters' responses. Regarding blood glucose target, there was highly significant differences between mothers and their daughter responses $\left(\chi^{2}=25.4954\right.$ with $p<.00001)$. While $27.5 \%$ of the mothers mentioned that their daughters have blood glucose target, $78.95 \%$ of the teen declared that they have blood glucose target. Surprisingly, mothers and their daughters didn't know the last glycated hemoglobin level. Concerning occurrence of hypoor hyperglycemia, responses of mothers and their daughters showed a highly significant difference. Regarding occurrence of hypoglycemia, $\chi^{2}$ was 14.0245 with $p<.001$. On the other hand, concerning hyperglycemia, $\chi^{2}$ was 60.0231 with $p<.000001$.

Table 6 illustrated knowledge of type I diabetic teen females and their mothers regarding diabetes self-management. Results indicated that there is a highly significant difference between teens and their mothers, where $p$-value of $\chi^{2}$ test always is less than .05 . 
Table 5. Measuring glucose level practices among studied subjects from girls and mothers responses

\begin{tabular}{|c|c|c|c|c|c|c|}
\hline \multirow{2}{*}{ Measuring Glucose level practices } & \multicolumn{2}{|c|}{ Mothers $(\mathbf{N}=150)$} & \multicolumn{2}{|c|}{ Girls $(\mathbf{N}=150)$} & \multirow{2}{*}{$\chi^{2}$} & \multirow{2}{*}{$p$} \\
\hline & $\mathbf{n}$ & $\%$ & $\mathbf{n}$ & $\%$ & & \\
\hline \multicolumn{7}{|l|}{ Measuring glucose level at home } \\
\hline Yes & 40 & 26.67 & 57 & 38.00 & \multirow{2}{*}{4.4030} & \multirow{2}{*}{$.0359 *$} \\
\hline No & 110 & 73.33 & 93 & 62.00 & & \\
\hline \multicolumn{7}{|l|}{ What kind of test** } \\
\hline Using glucometer & 40 & 100 & 48 & 84.21 & \multirow{2}{*}{5.2103} & \multirow{2}{*}{$.0224 *$} \\
\hline Using urine strips & 0 & 0 & 9 & 15.79 & & \\
\hline \multicolumn{7}{|c|}{ How often you measure glucose level** } \\
\hline Once a day & 23 & 57.50 & 36 & 63.16 & \multirow{3}{*}{4.1368} & \multirow{3}{*}{.1264} \\
\hline Twice or more a day & 0 & 0 & 6 & 10.53 & & \\
\hline Once or more every week & 17 & 42.50 & 15 & 26.32 & & \\
\hline \multicolumn{7}{|l|}{ When you measure glucose level** } \\
\hline Before breakfast (pre-prandial) & 32 & 80.00 & 36 & 63.16 & \multirow{3}{*}{3.5806} & \multirow{3}{*}{.1669} \\
\hline Two hours after meal & 8 & 20.00 & 15 & 26.32 & & \\
\hline Before bed time & 0 & 0 & 6 & 10.53 & & \\
\hline \multicolumn{7}{|l|}{ Have blood glucose level target** } \\
\hline Yes & 11 & 27.50 & 45 & 78.95 & \multirow{2}{*}{25.4954} & \multirow{2}{*}{$4.43 \times 10^{-7} *$} \\
\hline No & 29 & 72.50 & 12 & 21.05 & & \\
\hline \multicolumn{7}{|l|}{ Know last glycated hemoglobin level } \\
\hline Yes & 0 & 0 & 0 & 0 & \multirow{2}{*}{0.0000} & \multirow{2}{*}{1.000} \\
\hline No & 150 & 100.00 & 150 & 100.00 & & \\
\hline \multicolumn{7}{|c|}{ Suffered from low blood glucose level (Hypoglycemia) before } \\
\hline Yes & 16 & 10.67 & 9 & 6.00 & \multirow{3}{*}{14.0215} & \multirow{3}{*}{$.0009 *$} \\
\hline No & 108 & 72.00 & 87 & 58.00 & & \\
\hline Don’t know & 26 & 17.33 & 54 & 36.00 & & \\
\hline \multicolumn{7}{|c|}{ Suffer from high blood glucose level (Hyperglycemia) before } \\
\hline Yes & 10 & 6.67 & 42 & 28.00 & \multirow{3}{*}{60.0231} & \multirow{3}{*}{$9.25 \times 10^{-14 *}$} \\
\hline No & 114 & 76.00 & 48 & 32.00 & & \\
\hline Don’t know & 26 & 17.33 & 60 & 40.00 & & \\
\hline
\end{tabular}

Considering carbohydrate source in diet, $46 \%$ of mothers chose the right answer which is bread and cereals. On the other hand, Considerable percentage of teens $(80 \%)$ of teens got the correct answer. Accordingly, $\chi^{2}$ results (40.5179) indicated a statistically high significant difference $(p<.00001)$ Regarding effect of non-sugared fruit juice, percentage of teens chose the right answer was highly exceed the percent of mothers how chose that it increase blood glucose level; $14 \%$ and $2 \%$ respectively. Results showed a highly significant difference where $\chi^{2}$ was 13.0616 with $p<.005$.

Regarding the effect of physical exercise, $66 \%$ of mothers compared to $40 \%$ of teens replayed that it decrease blood glucose level. Statistical analysis showed a highly significant difference ( $\chi^{2}$ was 31.6570 wit $p$ less than .000001 ).

Questionnaire also consider daily self-management in different situation; like action to be taken when getting morning insulin dose and missing breakfast or when getting lunch if missed morning insulin dose. In those situations, percentage of diabetic teen females right replays considerably exceeds percentage of mothers right replays. In the former situation, $5.33 \%$ of mothers and $28 \%$ of daughters chose the right action to be taken. In the later situation, $18 \%$ of mothers and $30 \%$ of teens chose the right action. Statistical analysis of the responses showed highly significant differences where $p$-values in the two question was less than .000001 .

Considering the ideal blood glucose level which between 90 and $130 \mathrm{mg}$, percentage of mothers and daughters who chose the right answer was comparable; $35.33 \%$ and $36 \%$ respectively. No significant difference between the answers have been detected. Considering glycated hemoglobin test which reflect the average blood glucose level for the last 6 months, percentage of teens who chose the right answer was double the percentage of mothers; $32 \%$ and $16 \%$ respectively. 
Surprisingly, considerable percentage of mothers and their daughter don't know the significant of this test, $84 \%$ and $56 \%$ respectively. Statistical analysis showed a highly significant difference between teen females and their mothers (where $\chi^{2}$ was 29.602 with $\left.p<.000001\right)$.

Table 7 summarized knowledge of type I diabetic teen females and their mothers regarding blood glucose level. About symptoms of hypoglycemia, percentage of mothers who know the right symptom was outnumber percentage of teens who know the symptom; $44.67 \%$ and $16 \%$ respectively. The same was noticed with the reason of hypoglycemia, where $50 \%$ of mothers distinguished the right reason while only $28 \%$ of their daughters did. Concerning action to be taken in hypoglycemia, $64 \%$ of mothers and only $16 \%$ of teens recognized the right action. Generally, regarding hypoglycemia mothers knowledge level is proceed the knowledge level of their daughters. Statistical analysis showed a highly significant difference where $p$-values was always less than .001.

Table 6. Knowledge regarding healthy diet, exercise, insulin dose and glucose monitoring among studied subjects

\begin{tabular}{|c|c|c|c|c|c|c|}
\hline \multirow{2}{*}{ Knowledge regarding Diabetes Self -care Management } & \multicolumn{2}{|c|}{ Mothers $(\mathrm{N}=150)$} & \multicolumn{2}{|c|}{ Girls $(\mathbf{N}=150)$} & \multirow{2}{*}{$\chi^{2}$} & \multirow{2}{*}{$p$} \\
\hline & n & $\%$ & n & $\%$ & & \\
\hline \multicolumn{7}{|l|}{ Source for carbohydrate in the diet } \\
\hline Oil \& fats & 53 & 35.33 & 21 & 14.00 & \multirow{4}{*}{40.5179} & \multirow{4}{*}{$8.27 \times 10^{-9} *$} \\
\hline Vegetables & 0 & 0 & 3 & 2.00 & & \\
\hline Bread \& cereals & 69 & 46.00 & 120 & 80.00 & & \\
\hline Don’t know & 28 & 18.67 & 6 & 4.00 & & \\
\hline \multicolumn{7}{|c|}{ What is the effect of non-sugared fruit juice on blood glucose level } \\
\hline Decrease blood glucose level & 5 & 3.33 & 3 & 2.00 & \multirow{4}{*}{13.0616} & \multirow{4}{*}{$.0045^{*}$} \\
\hline Increase blood glucose level & 3 & 2.00 & 21 & 14.00 & & \\
\hline Doesn’t affect & 117 & 78.00 & 102 & 68.00 & & \\
\hline Don’t know & 25 & 16.67 & 24 & 16.00 & & \\
\hline \multicolumn{7}{|l|}{ What is the effect of physical exercise on diabetics } \\
\hline Decrease blood glucose level & 99 & 66.00 & 60 & 40.00 & \multirow{4}{*}{31.6570} & \multirow{4}{*}{$6.18 * 10^{-7 *}$} \\
\hline Increase blood glucose level & 0 & 0 & 12 & 8.00 & & \\
\hline Doesn’t affect & 6 & 4.00 & 0 & 0 & & \\
\hline Don’t know & 45 & 30.00 & 78 & 52.00 & & \\
\hline \multicolumn{7}{|c|}{ If the girl has morning insulin dose and doesn't has her breakfast } \\
\hline Decrease blood glucose level & 8 & 5.33 & 42 & 28.00 & \multirow{4}{*}{62.2663} & \multirow{4}{*}{$1.93 \times 10^{-13 *}$} \\
\hline Increase blood glucose level & 99 & 66.00 & 42 & 28.00 & & \\
\hline Doesn’t affect & 11 & 7.33 & 39 & 26.00 & & \\
\hline Don’t know & 32 & 21.33 & 27 & 18.00 & & \\
\hline \multicolumn{7}{|c|}{ What should do if, in lunch time discovered that morning insulin dose have been missed } \\
\hline Check blood glucose level to determine the proper dose & 27 & 18.00 & 45 & 30.00 & \multirow{4}{*}{35.1331} & \multirow{4}{*}{$1.14 \times 10^{-7} *$} \\
\hline Has the same dose which been missed & 73 & 48.67 & 24 & 16.00 & & \\
\hline Get doubled insulin dose & 3 & 2.00 & 3 & 2.00 & & \\
\hline Don’t know & 47 & 31.33 & 78 & 52.00 & & \\
\hline \multicolumn{7}{|l|}{ Ideal blood glucose level for diabetics } \\
\hline $90-130 \mathrm{mg}$ & 53 & 35.33 & 54 & 36.00 & \multirow{4}{*}{9.4889} & \multirow{4}{*}{$.0234^{*}$} \\
\hline $40-70 \mathrm{mg}$ & 5 & 3.33 & 15 & 10.00 & & \\
\hline $10-200 \mathrm{mg}$ & 13 & 8.67 & 21 & 14.00 & & \\
\hline Don’t know & 79 & 52.67 & 60 & 40.00 & & \\
\hline \multicolumn{7}{|c|}{ Glycated hemoglobin test is a test for the average blood glucose level for } \\
\hline One week & 0 & 0 & 6 & 4.00 & \multirow{4}{*}{29.6020} & \multirow{4}{*}{$1.67 \times 10^{-6 *}$} \\
\hline $6-10$ weeks & 0 & 0 & 12 & 8.00 & & \\
\hline 6 months & 24 & 16.00 & 48 & 32.00 & & \\
\hline Don’t know & 126 & 84.00 & 84 & 56.00 & & \\
\hline
\end{tabular}

$* p<.05$ 
Table 7. Knowledge regarding hypoglycemia and hyperglycemia among studied subjects

\begin{tabular}{|c|c|c|c|c|c|c|}
\hline \multirow{2}{*}{ Knowledge regarding Hypoglycemia and Hyperglycemia } & \multicolumn{2}{|c|}{ Mothers $(\mathbf{N}=150)$} & \multicolumn{2}{|c|}{ Girls $(\mathbf{N}=\mathbf{1 5 0})$} & \multirow{2}{*}{$\chi^{2}$} & \multirow{2}{*}{$p$} \\
\hline & $\mathbf{n}$ & $\%$ & $\mathbf{n}$ & $\%$ & & \\
\hline \multicolumn{7}{|l|}{ Symptom of low blood glucose level (Hypoglycemia) is } \\
\hline Increase thirst \& frequent urination & 22 & 14.67 & 3 & 2.00 & \multirow{4}{*}{54.9072} & \multirow{4}{*}{$7.19 \times 10^{-12} *$} \\
\hline Diabetic coma & 67 & 44.67 & 24 & 16.00 & & \\
\hline Breath that smells fruity & 0 & 0 & 9 & 6.00 & & \\
\hline Don’t know & 61 & 40.67 & 114 & 76.00 & & \\
\hline \multicolumn{7}{|l|}{ Low blood glucose level is due to } \\
\hline High insulin dose & 75 & 50.00 & 42 & 28.00 & \multirow{4}{*}{16.3344} & \multirow{4}{*}{$.0010^{*}$} \\
\hline Low insulin dose & 6 & 4.00 & 12 & 8.00 & & \\
\hline Excess food intake & 3 & 2.00 & 12 & 8.00 & & \\
\hline Don’t know & 66 & 44.00 & 84 & 56.00 & & \\
\hline \multicolumn{7}{|l|}{ If the girl suffer from hypoglycemia should } \\
\hline Has insulin dose & 0 & 0 & 12 & 8.00 & \multirow{4}{*}{72.3139} & \multirow{4}{*}{$1.36 \times 10^{-15 *}$} \\
\hline Rest & 12 & 8.00 & 30 & 20.00 & & \\
\hline Has some sweets or sugared juice & 96 & 64.00 & 24 & 16.00 & & \\
\hline Don’t know & 42 & 28.00 & 84 & 56.00 & & \\
\hline \multicolumn{7}{|l|}{ High blood glucose level (Hyperglycemia) is due to } \\
\hline Insufficient insulin dose & 74 & 49.33 & 24 & 16.00 & \multirow{4}{*}{42.7721} & \multirow{4}{*}{$2.75 \times 10^{-9} *$} \\
\hline Delay in having meals & 6 & 4.00 & 30 & 20.00 & & \\
\hline Delay in having snacks & 2 & 1.33 & 3 & 2.00 & & \\
\hline Don’t know & 68 & 45.33 & 93 & 62.00 & & \\
\hline \multicolumn{7}{|l|}{ Symptom of high blood glucose level (Hyperglycemia) is } \\
\hline Sweaty \& shaky & 11 & 7.33 & 21 & 14.00 & \multirow{4}{*}{26.1930} & \multirow{4}{*}{$8.69 \times 10^{-6 *}$} \\
\hline Dizziness & 11 & 7.33 & 39 & 26.00 & & \\
\hline Breath that smells fruity & 29 & 19.33 & 18 & 20.00 & & \\
\hline Don’t know & 99 & 66.00 & 60 & 40.00 & & \\
\hline \multicolumn{7}{|l|}{ If the girl suffer from hyperglycemia should } \\
\hline Check blood glucose level to determine the proper dose & 21 & 14.00 & 33 & 22.00 & \multirow{4}{*}{29.2153} & \multirow{4}{*}{$2.02 \times 10^{-6} *$} \\
\hline Rest & 83 & 55.33 & 39 & 26.00 & & \\
\hline Has some sweets or sugared juice & 3 & 2.00 & 18 & 12.00 & & \\
\hline Don’t know & 43 & 28.67 & 60 & 40.00 & & \\
\hline
\end{tabular}

Regarding reason of hyperglycemia, percentage of who chose the right answer was outnumbered the percentage of teens who chose the right answer; $49.33 \%$ and $16 \%$ respectively. There was highly significant difference between mothers and their daughters' answers, where $\chi^{2}$ was 42.7721 with P-value $<0.000001$. About symptoms of hyperglycemia, percentage of mothers who know the right symptom was comparable to percentage of teens who know the symptom; $19.33 \%$ and $20 \%$ respectively. Considerably high percentage of mothers and their daughters didn't know the symptoms of hyperglycemia, $66 \%$ and $40 \%$ respectively. Statistical analysis showed a highly significant differences between responses of mothers and their daughters in this respect, where $\chi^{2}$ was 26.1930 with $p<.000001$. Concerning action to be taken in hyperglycemia, only $14 \%$ of mothers and $22 \%$ of teens recognized the right action. Statistical analysis showed a highly significant differences between responses of moth- ers and their daughters in this respect, where $\chi^{2}$ was 29.2153 with $p<.000001$.

Table 8 summarized knowledge of type I diabetic teen females and their mothers regarding foot care. Regarding better way for foot care, $52 \%$ of mothers and $64 \%$ of teen females knew the right way. Also, statistical analysis showed a highly significant differences between responses of mothers and their daughters in this respect, where $\chi^{2}$ was 19.1215 with $p<.000001$. About importance of foot care, $16.67 \%$ of mothers and $26 \%$ of teen females identified the importance of proper foot care. Meanwhile, considerable percentage of mothers (68\%) and teen females (58\%) didn't know the importance of proper foot care. Thus, statistical analysis didn't show any significant differences between responses of mothers and their daughters in this respect, where $\chi^{2}$ was 4.3590 with $p$-value of .2252 . 
Table 8. Knowledge regarding diabetic foot care among studied subjects

\begin{tabular}{|c|c|c|c|c|c|c|}
\hline \multirow{2}{*}{ Diabetic Foot Care } & \multicolumn{2}{|c|}{ Mothers $(\mathrm{N}=150)$} & \multicolumn{2}{|c|}{ Girls $(\mathbf{N}=150)$} & \multirow{2}{*}{$\chi^{2}$} & \multirow{2}{*}{$p$} \\
\hline & $\mathbf{n}$ & $\%$ & $\mathbf{n}$ & $\%$ & & \\
\hline \multicolumn{7}{|l|}{ Better way for foot care is } \\
\hline Examined \& wash daily & 78 & 52.00 & 96 & 64.00 & \multirow{4}{*}{19.1215} & \multirow{4}{*}{$7.04 \times 10^{-5 *}$} \\
\hline Wearing bigger shoes & 0 & 0 & 12 & 8.00 & & \\
\hline Soak in water for an hour daily & 0 & 0 & 0 & 0 & & \\
\hline Don’t know & 72 & 48.00 & 42 & 28.00 & & \\
\hline \multicolumn{7}{|c|}{ Better foot care is important because diabetics suffer from } \\
\hline Narrowing of blood vessels (arteries) & 6 & 4.00 & 3 & 2.00 & \multirow{4}{*}{4.3590} & \multirow{4}{*}{.2252} \\
\hline Poor blood supply & 17 & 11.33 & 21 & 14.00 & & \\
\hline All of the above & 25 & 16.67 & 39 & 26.00 & & \\
\hline Don’t know & 102 & 68.00 & 87 & 58.00 & & \\
\hline
\end{tabular}

$* p<.05$

Table 9 summarized knowledge of type I diabetic teen fe- cose level; 56.67\% and 76\% respectively, statistical analysis males and their mothers regarding diabetes complications. showed a highly significant difference between responses of Considerable percentages of mothers and their daughters mothers and their daughters, where $\chi^{2}$ was 112.4665 with $p$ don't know about inflammations influence on blood glu- $<.000001$.

Table 9. Knowledge regarding diabetes complications among studied subjects

\begin{tabular}{|c|c|c|c|c|c|c|}
\hline \multirow{2}{*}{ Knowledge regarding complications } & \multicolumn{2}{|c|}{ Mothers $(\mathrm{N}=150)$} & \multicolumn{2}{|c|}{ Girls $(N=150)$} & \multirow{2}{*}{$\chi^{2}$} & \multirow{2}{*}{$p$} \\
\hline & $\mathbf{n}$ & $\%$ & $\mathbf{n}$ & $\%$ & & \\
\hline \multicolumn{7}{|l|}{ Inflammations may cause } \\
\hline Increase blood glucose level & 42 & 28.00 & 18 & 12.00 & \multirow{4}{*}{112.4665} & \multirow{4}{*}{$2.17 \times 10^{-23 *}$} \\
\hline Decrease blood glucose level & 0 & 0 & 0 & 0 & & \\
\hline Doesn't affect blood glucose & 23 & 15.33 & 18 & 12.00 & & \\
\hline Don’t know & 85 & 56.67 & 114 & 76.00 & & \\
\hline \multicolumn{7}{|l|}{ Numbness \& tingling may be symptoms of } \\
\hline Kidney dysfunction & 6 & 4.00 & 9 & 6.00 & \multirow{4}{*}{33.2823} & \multirow{4}{*}{$2.18 \times 10^{-7} *$} \\
\hline Nerve damage (neuropathy) & 116 & 77.33 & 66 & 44.00 & & \\
\hline Eye defect & 0 & 0 & 3 & 2.00 & & \\
\hline Don't know & 28 & 18.67 & 72 & 48.00 & & \\
\hline \multicolumn{7}{|l|}{ If the girl suffer from influenza should } \\
\hline Decrease insulin dose & 3 & 2.00 & 9 & 6.00 & \multirow{4}{*}{9.004} & \multirow{4}{*}{$.0111^{*}$} \\
\hline Check blood glucose from time to time & 14 & 9.33 & 30 & 20.00 & & \\
\hline Has more protein & 0 & 0 & 0 & 0 & & \\
\hline Don’t know & 133 & 88.67 & 111 & 74.00 & & \\
\hline \multicolumn{7}{|l|}{ Diabetes complications includes } \\
\hline Neuropathy, impaired kidney functions and damage eyes & 96 & 64.00 & 60 & 40.00 & \multirow{4}{*}{18.5244} & \multirow{4}{*}{$.0003 *$} \\
\hline Respiratory problems & 6 & 4.00 & 3 & 2.00 & & \\
\hline No effects & 2 & 1.33 & 6 & 4.00 & & \\
\hline Don’t know & 46 & 30.67 & 81 & 54.00 & & \\
\hline
\end{tabular}

$* p<.05$

Numbness and tingling may be symptoms of nerve damage (neuropathy). Considerable high percentage of mothers (77.33\%) know that compared with only $44 \%$ of their daughters. High percentage of teen females (44\%) don't know

Published by Sciedu Press about this detail. Regarding this detail, statistical analysis showed a highly significant difference between mothers and their daughters responses, where $\chi^{2}$ was 33.2833 with $p<$ .000001 . Concerning action to be taken in case of influenza, 
considerable low percentage of mothers (only 9.33\%) and teens females $(20 \%)$ recognized the right action. Considerably high percentage of mothers $(88.67 \%)$ and teen females (74\%) don't know what kind of action should be taken. Statistical analysis show significant differences between responses of mothers and their daughters in this respect, where $\chi^{2}$ was 9.004 with $p<.05$.

Regarding diabetes complications, considerable percentage of mothers $(64 \%)$ compared to moderate percentage of teen females $(40 \%)$ distinguish the right complications. Considerably high percentage of teen females (54\%) didn't know diabetes complications. Statistical analysis showed a highly significant differences between responses of mothers and their daughters in this respect, where $\chi^{2}$ was 18.5244 with $p<.001$. When $p$-value less than 0.05 there is a significant difference.

In Table 10, statistical comparison of knowledge level about diabetes and diabetes self-management practices between mothers and their daughters have been summarized. Mothers knowledge level varied between 0 and $85 \%$ with an average of 38.300 and standard deviation of 25.103. On the other hand teen females knowledge level varied between 0 and $90 \%$ with an average of 29.8 and standard deviation of 24.658. $T$-test statistical analysis showed that there is highly significant difference between the average knowledge level between mothers and their daughters, where $t$-statistics was 2.9585 with $p$-value of .001669 which is less than .05 . To examine if there is a correlation between mothers' knowledge level and their daughters' knowledge level, correlation coefficient have been calculated. The correlation coefficient was 0.02303 with a $p$-value of .7797 . This indicated that the correlation coefficient is non-significantly differ from zero; i.e. there is no correlation exist between mothers' knowledge level and their daughters' knowledge level.

Figure 1 summarized the relation between mothers' char- acteristics and their knowledge level about diabetes selfmanagement. Regarding to mothers' age, statistical analysis showed a highly significant difference in mothers' knowledge level with respect to her age, where $\chi^{2}$ was 22.1502 with $p<.000001$. This indicated that mothers' age play a considerable part in her acquired experience.

Table 10. Comparison between knowledge level about diabetes among studied subjects type I diabetic teenage females and their mothers

\begin{tabular}{|c|c|c|}
\hline \multirow{2}{*}{$\begin{array}{l}\text { Socio-demographic } \\
\text { characteristics of mother }\end{array}$} & \multicolumn{2}{|l|}{$n=300$} \\
\hline & Frequency & Percent (\%) \\
\hline \multicolumn{3}{|l|}{ Mother age } \\
\hline$<30$ years & 24 & 16.00 \\
\hline-35 years & 28 & 18.67 \\
\hline$>35$ years & 98 & 65.33 \\
\hline$\mu \pm \sigma$ & \multicolumn{2}{|l|}{$36.6 \pm 4.9092$} \\
\hline \multicolumn{3}{|l|}{ Mother's educational level } \\
\hline Illiterate & 15 & 10.00 \\
\hline Read and write & 20 & 13.33 \\
\hline Primary & 19 & 12.67 \\
\hline Intermediate & 27 & 18.00 \\
\hline Secondary & 45 & 30.00 \\
\hline University graduate & 24 & 16.00 \\
\hline \multicolumn{3}{|l|}{ Mother's employment } \\
\hline Working & 58 & 38.67 \\
\hline House-wife & 92 & 61.33 \\
\hline \multicolumn{3}{|l|}{ Girls Age } \\
\hline$<16$ years & 54 & 36.00 \\
\hline 16-19 years & 96 & 64.00 \\
\hline$\mu \pm \sigma$ & \multicolumn{2}{|l|}{$16.42 \pm 1.4448$} \\
\hline \multicolumn{3}{|l|}{ Girls education level } \\
\hline Read and write & 6 & 4.00 \\
\hline Primary & 42 & 28.00 \\
\hline Intermediate & 75 & 50.00 \\
\hline Secondary & 27 & 18.00 \\
\hline \multicolumn{3}{|l|}{ Rank Among Brothers } \\
\hline First & 21 & 14.00 \\
\hline Second & 48 & 32.00 \\
\hline Third & 60 & 40.00 \\
\hline Others & 21 & 14.00 \\
\hline
\end{tabular}

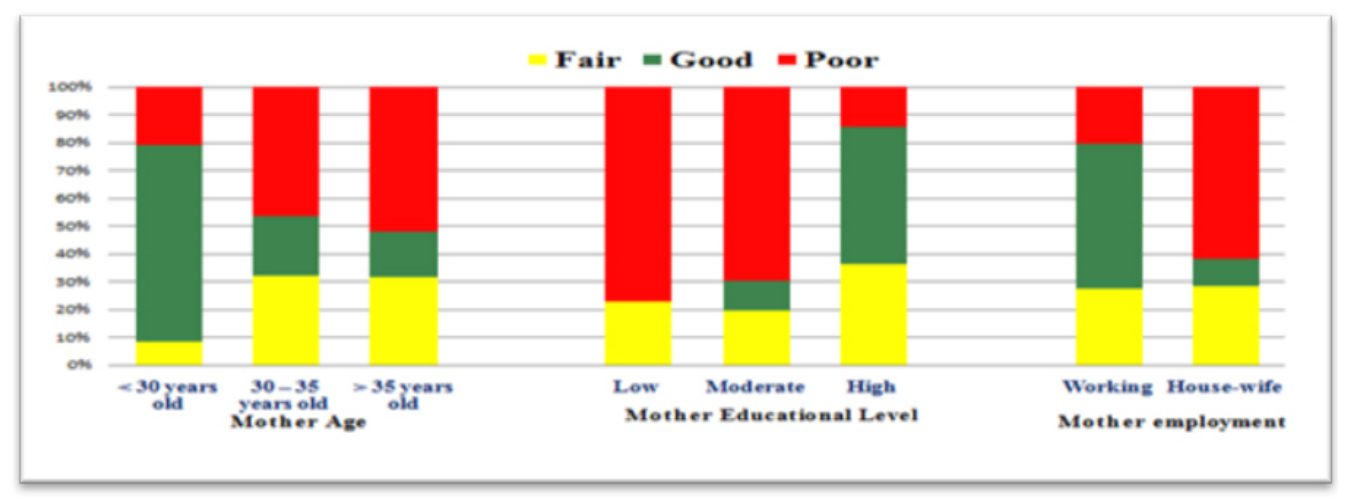

Figure 1. Variation of mothers' knowledge level regarding diabetes self-management with mothers' characteristics 
Regarding mothers' educational level, statistical analysis showed a highly significant difference in mothers' knowledge level with respect to her educational level, where $\chi^{2}$ was 24.4585 with $p<.000001$. It is obvious that as mothers' educational level increase percentage of mothers with Good knowledge increase. This indicated that mothers' educational level take an important role in her acquired knowledge and information.

Concerning mothers' employment, statistical analysis showed a highly significant difference in mothers' knowledge level with respect to employment, where $\chi^{2}$ was 37.2433 with $p<.000001$. It is obvious that percentage of employed mothers with Good knowledge exceed the percentage of housewives with Good knowledge. Contingency coefficient showed high association between employment and knowledge level.

\section{Discussion}

Type 1 diabetes requires life-long treatment and failure to adhere to treatment plans can increase the possibility that the serious complications of the condition may occur. Teenagers are noted to be particularly at risk of failing to manage their diabetes well. This is also the age at which many young people are first diagnosed with the condition. Puberty and the other developmental changes that take place at this stage of life add to the difficulties that teenagers may be experiencing. ${ }^{[18]}$ In the case of type 1 diabetes it is particularly difficult to manage treatment for teenagers due to the effects of changes during puberty combined with poor selfmanagement and a higher level of insulin sensitivity in that age group. ${ }^{[19]}$

Knowledge is the greatest weapon in the fight against diabetes mellitus. Information can help people assess their risk of diabetes, motivate them to seek proper treatment and care, and inspire them to take charge of their disease. ${ }^{[20,21]}$ During adolescence knowledge and skills are acquired for establishing adult roles. For teenagers with diabetes knowledge and applying this knowledge become essential for prevention of many complications. Moreover, young people with diabetes have an alteration to mature life. ${ }^{[22]}$ On the other hand, mother can play a pivotal role in the adolescent's acquisition of the initial knowledge and skills to have a healthy life with diabetes. $^{[23]}$

The present study revealed that, about half of the mother finished secondary school or university graduated $(32 \%, 16 \%)$ respectively instead of the result reflected the level of knowledge still not good about diabetes management, result similar to another research. ${ }^{[10]}$ On the other hand, another study mentioned that poor health is more common among parent

Published by Sciedu Press who have low education level. ${ }^{[24,25]}$

Socioeconomic, demographic characteristic and having knowledge about diabetic highly contributes in the management of diabetes especially type I diabetes in adolescence. ${ }^{[26]}$ In Saudi Arabia in general and at Abha city in particular most of community member as the finding of the study live with extended family, the size of family big (7-more than 10) and the income more the 7000 SR (about $95 \%$ of the sample) all the previous factors interfere with poor mother knowledge and reflect on her daughter disease management as it was found that family size highly contributed in poor mother knowledge. As well as family in community. Similar result was obtained from other researcher. ${ }^{[27-29]}$ Therefore, the pediatric nurse must concentrate on concept of family-center care and education all the family at the community and it is necessary for the nurse to know the demographic profile of the target audience, so that appropriate programs are made available.

Results of the present study reflect that only $7 \%$ of the teens had not complain of any complications while $93 \%$ had one problem, numbness and tingling of feet, teeth and oral problems, depression, etc. although the previously mention issued, only $50 \%, 72 \%$ respectively had no regular visits to diabetic clinics and didn't attend any health education session. These results show that it is important to gain such information in order to be able to create an effective and tailored health education and promoting program bout the importance of previous aspect. ${ }^{[30]}$

Present study findings reflected that the mothers don't aware or don't carefully follow their daughters in respect of diabetes self-management through diet, exercise, insulin therapy similar results has been noted in another studies. ${ }^{[31]}$

In contrast, there are another studies that reflects that the overall knowledge score of the mothers tended to be slightly higher than their daughters. ${ }^{[32]}$ Therefore, the pediatric nurse need to teach the mother to support their daughters behavioral change, efforts to promote physical activity and they should understand the normal stage of childhood and adolescent development and how they affect the diabetes management.

Regarding the type of insulin used, $14 \%$ of the diabetic teens stated that they don't know the type of insulin they use and only $38 \%$ of the diabetic teens had regular checkups for their glucose level, more than two thirds mentioned that they measured their glucose level once daily, $42 \%$ had an attack of hypoglycemia several times before collecting the data in this research. Also $68 \%$ of the teens stated that they had one or more attacks of hyperglycemia. As the primary goal for any patient with DM is to prevent the onset of acute 
hypo-hyper glycaemia, DKA and chronic complications e.g.: microvascular, microvascular complications. Moreover, in adolescence the physiological and psychological effects of puberty play an important role in the patient's ability to adequately control blood glucose concentrations. The adolescent generally has increasing autonomy with decreasing parental supervision near - normal glucose concentration should be the goal as the individual patient mature and teaching must be individualized and must be discussed with the family. At Abha city it is observed the lack of proper facilities for screening of diabetes and identifying the high risk groups. Also, it's observed that $19 \%$ of the diabetic teen family members don't know that these girls have DM, this may reflect that this city sometime the mother consider announcing about the disease is a "shame" to tell everyone that her daughter has DM also some mothers try to hide their daughter's diabetes from relatives because they consider it as sigma result similar to other research. ${ }^{[32,33]}$ Therefore, the pediatric nurse must understand the socio-demographical characteristics of people with diabetes before developing diabetes, related health care education or the program, materials or activities. As mentioned on other research, how adolescents manage information should be understood within the culturally embedded parents and peers' relationship process. ${ }^{[34,35]}$

Knowledge of type I diabetes teen females and their mothers regarding diabetes complications showed that almost half of the sample doesn't know the effect of inflammation, influenza, etc. on their health condition and they don't know the effect of diabetes on their general health this is similar to the results observed by Murugesam et al. (2007) and AlShafaee (2008). ${ }^{[36,37]}$ These results indicate that there is a need to improve the knowledge of teen diabetics and their mothers' hospital and primary care about early and late complications so that they be able to have better management of their cases.

Finally, the mother characteristics, family socio-demographic characteristics as well as family history with diabetes didn't contribute in the teen females' knowledge level about diabetes and diabetes self-management. The only factor which has a significant influence on teen females' knowledge was the duration since diagnosed as diabetes. Accordingly, the researcher could concluded that teen females' knowledge level depends only upon the personal experience which accumulated by time.

\section{Implication}

This study is unique in that it to assess the knowledge of Saudi female teenagers and their mothers regarding management of type I DM. Diabetes nurse educators need to include mothers when discussing these very important issues with teenagers. Diabetes nurse educators can assist mothers in their discussions with their daughters by making sure that mothers have the correct information. Mothers can be taught how to capitalize on "every triggers" to initiate or resume conversations with their daughters. Nurse educators should recognize that discussions between mothers and adolescent daughters are still difficult especially during period of teenage (13-19 years).

\section{Conclusion}

Based on the finding of the present study, it is concluded that both mother and their daughter had lack of awareness and knowledge in most of aspects of diabetes management and the is no correlation exist between mother's and daughter's knowledge regarding diabetic management.

Mother's age, the educational level and mother's employment are show high significant in mother knowledge level while the diabetic teenage females' knowledge level depends only on the duration since diagnosed as diabetes. Also, the diabetic teenage females did not attend any health education in spite of having too much complication.

According to the results of the present study, the following recommendations are suggested:

(1) The researcher suggested family-based interventions and integrated ongoing programs of education, monitoring and support for young people and their families living with diabetes are needed.

(2) Educational programs should target the community with the help of religious leaders as well as other social groups including schools. It should involve all aspects of diabetes management through a variety of channels "radio, television, newspapers, internet and formal group talks" such information gathered should be delivered in local languages.

(3) All health education programs must start in the childhood period to help the child and her family have a better insight on their responsibility to embrace healthy behaviours in order to achieve long term control of the diabetes and its complications.

(4) Implementation of home visit programs in cities such as "Abha" to follow up with and encourage mothers and families to be involved in the decision making process, supporting and influencing teenagers develop competencies and responsibility towards diabetic management.

(5) Adolescence is a crucial time for effective type 1 diabetes mellitus management because of the complications in harmonizing diabetes self-management and the growing needs in this period. Schools are special 
environments for teenagers with type 1 diabetes mellitus, since their diabetes self-management attitudes are stimulated by and affects their growth, the support they get for diabetes self-management from school personnel such as school teachers and nurses should be emphasized.

\section{ACKNOWLEDGEMENTS}

The authors are thankful to the Deanship of Scientific Research, College of Nursing Research Center at King Saud University for funding this research.

\section{CONFLicts OF INTEREST Disclosure}

The authors declare that there is no conflict of interest.

\section{REFERENCES}

[1] Eisenbarth GS, Buse JB. Type 1 diabetes mellitus. In: Melmed S, Polonsky KS, Larsen PR, Kronenberg HM, eds. Williams Textbook of Endocrinology. 12th ed. Philadelphia, Pa.: Elsevier Saunders; chap 32. 2011. https://doi . org/10.1016/B978-1-4377-032 4-5.00032-8

[2] Al-Khadi YM. Quality of diabetic care in family practice centre, Aseer Region, Saudi Arabia. J Health Spec. 2014; 2: 109-13. https://doi.org/10.4103/1658-600X.137886

[3] Fowler MJ. Microvascular and Macrovascular Complications of diabetes clinical Diabetes. 2008; 26: 277-82.

[4] Diabetes Control and Complications Trial Research Group. Effect of intensive diabetes treatment on the development and progression of long-term complications in adolescents with insulindependent diabetes mellitus. Journal of Pediatrics. 1994; 125: 177188. https://doi .org/10.1016/S0022-3476(94)70190-3

[5] Deltsidou A, Lemonidou C, Zarikas V, et al. Oligomenorrhoea in adolescents with type 1 diabetes mellitus: relationship to glycaemic control. European Journal of Obstetrics \& Gynecology and Reproductive. 2010; 153: 62-66. PMid:20702019 https : //doi .org/10 .1016/j . ejogrb. 2010.07.027

[6] Livshits A1, Seidman DS. Fertility issues in women with diabetes. Womens Health (LondEngl). 2009; 5(6): 701-7. PMid:19863473 https://doi.org/10.2217/whe.09.47

[7] Majumder N, Majumder N, Datta S. Knowledge and perception of mothers of under five children regarding etiology of type-II diabetes mellitus in Agartala, Tripura. Health. 2013; 1(3): 64-70.

[8] Oskouie F, Mehrdad N, Ebrahimi H. Mediating factors of coping process in parents of children with type 1 diabetes. Journal of Diabetes and Metabolic Disorders. 2013. PMid:23673161 https: //doi.org/10.1186/2251-6581-12-20

[9] Maslakpak M, Ahmadi F, Feizi A. Parents' worries about life problems of adolescent girls with diabetes: a qualitative study. Hayat. 2011; 17(1): 5-15.

[10] Al-Odayani AN, Alsharqi OZ, Ahmad AM, et al. Children's glycemic control: mother's knowledge and socioeconomic status. Glob J Health Sci. 2013; 5(6): 214-26.

[11] KyngAs HA, Kroll T, Duffy ME. Compliance of adolescents with diabetes. J PediatrNurs. 2000; 15(4): 260-7. PMid:10969500 https : //doi.org/10.1053/jpdn.2000.6169

[12] Moodley LM, et al. An assessment of the level of knowledge about diabetes mellitus among diabetic patients in a primary healthcare setting, South African Family Practice. 2007; 49(10): 16-16. https://doi.org/10.1080/20786204.2007.10873652

[13] Wong Dl, Hockenberry MJ. Wong's Nursing Care of Infants and Children. 7th edition. St Louis: Mosby Combany. 2003. 1861-1880 p.

Published by Sciedu Press
[14] Wu YP, Hilliard ME, Rausch J, et al. Family involvement with the diabetes regimen in young people: the role of adolescent depressive symptoms. Diabet Med. 2013; 30(5): 596-602.

[15] Al-Khaldi YM, et al. Availability of resources of diabetic care in primary health care settings in Aseer region, Saudi Arabia. Saudi Med J. 2002; 23 (12): 1509-1513. PMid:12518203

[16] Al-Herbish A, El-Mouzan M, Al-Salloum A, et al. Prevalence of type 1diabetes mellitus in Saudi Arabian children and adolescents. Saudi Med J. 2008; 29(9): 1285-1288. PMid:18813413

[17] American Diabetes Association. Standards of medical care in diabetes-2012. Diabetes Care. 2012.

[18] Keough L, Sullivan-Bolyai S, Crawford S, et al. Self-management of Type 1 diabetes across adolescence . The Diabetes Educator. 2011; 37(4): 486-500. PMid:21602489 https ://doi .org/10.1177/01 45721711406140

[19] Nabors L, Bartz J. Type I diabetes in children: Facilitating adherence to medical regimens. 2013.

[20] Noohuat E. Overview of glycemic control, knowledge, awareness and attitude among type-2 diabetes male patient's. App Pharm. 2015; 7(1): 75-82.

[21] Upadhyay DK, Palaian S, Shankar PR, et al. Knowledge, Attitude and Practice about Diabetes among Diabetes Patients in Western Nepal. Rawal Medical Journal. 2008; 33(1): 8-11.

[22] Dahlquist GG, Nyström L, Patterson CC. The Swedish Childhood Diabetes Study Group, \& the Diabetes Incidence in Sweden Study Group. Incidence of Type 1 Diabetes in Sweden Among Individuals Aged 0-34 Years, 1983-2007: An analysis of time trends. Diabetes Care. 2011; 34(8): 1754-1759. PMid:21680725 https: //doi.org/10.2337/dc11-0056

[23] Osborn P, Berg CA, Hughes AE, et al. What Mom and Dad Don't Know CAN Hurt You: Adolescent Disclosure to and Secrecy from Parents About Type 1 Diabetes. Journal of Pediatric Psychology. 2013; 38(2): 141-150. PMid:23009958 https://doi.org/10.1 093/jpepsy/jss102

[24] Kalichman SC, Benotsch E, Suarez T, et al. Health literacy and healthrelated knowledge among persons living with HIV/AIDS. Am J Prev Med. 2000; 18(4): 325-311. https://doi.org/10.1016/S074 9-3797 (00) 00121-5

[25] Raphael D, Anstice S, Raine K, et al. The social determinants of the incidence and management of type 2 diabetes mellitus: are we prepared to rethink our questions and redirect our research activities? Leadership in Health Services. 2003; 16(3): 10-20. https://doi.org/10.1108/13660750310486730

[26] Sivagnanam G, Namasivayam K, Rajasekaran M. Comparative Study of the Knowledge, Beliefs and Practices of Diabetic Patients Cared for at, Teaching Hospital (Free Service) and Those Cared for by Private Practitioners (Paid Service). Annals of the New York Academy Science. 2000; 958(1): 416-419. https://doi.org/10.1111/j. 1749-6632.2002.tb03016.x 
[27] Schillinger D, Grumback K, Piette J, et al. Association of health literacy with diabetes outcomes. Journal of the American Medical Association. 2005; 288(4): 475-482. https ://doi.org/10.100 $1 /$ jama.288.4.475

[28] Lindstrom C, Amaan J, Norberg AL. Parental burnout in relation to socio-demographic, psychosocial and personality factors as well as disease duration and glycaemic control in children with type 1 diabetes mellitus. ActaPaediatr. 2011; 100: 1011-1017. PMid:21414025 https://doi.org/10.1111/j.1651-2227.2011.02198.x

[29] Mckenzie JF, Neiger BL, Thackeray R. Planning, implementing, and evaluating health promotion programs (4th ed.). San Francisco: Pearson Benjamin Cummings. 2009.

[30] Brown AF, Ettner SL, Piette J. Socioeconomic position and health among persons with diabetes mellitus: a conceptual framework and review of the literature. Epidemiol Review. 2004; 26: 63 PMid:15234948 https://doi.org/10.1093/epirev/mxh002

[31] Charron-Prochownik D, Fischl AR, Choi J, et al. Mother-daughter dyadic approach for starting preconception counseling at puberty in girls with diabetes. Research Journal of Women's Health. 2014 https ://doi.org/10.7243/2054-9865-1-2
[32] Roeloffs C, Sherbourne C, Unützer J, et al. Stigma and depression among primary care patients. General Hospital Psychiatry. 2003; 25: 311-315. https://doi.org/10.1016/S0163-8343(03)0 0066-5

[33] Oskouie F, Ebrahimi H, Mehrdad N. Parental confrontation with type 1 diabetes in their children. Archives Des Sciences. 2012; 65(8).

[34] Brown AF, Ettner SL, Piette J. Socioeconomic position and health among persons with diabetes mellitus: a conceptual framework and review of the literature. Epidemiol Review. 2004; 26: 63-77. PMid:15234948 https://doi.org/10.1093/epirev/mxh002

[35] Brown BB, Bakken JP. Parenting and peer relationships: Reinvigorating research on familypeer linkages in adolescence. Journal of Research on Adolescence. 2011; 21: 153-165.

[36] Murugesan N, Snehalatha C, Shobhana R, et al. Awareness about diabetes and its complications in the general and diabetic population in a city in southern India. Diabetes Res. Clin. Pract. 2007; 77: 433-437. https://doi.org/10.1016/j.diabres.2007.01.004

[37] Al Shafaee MA, Al-Shukaili S, Rizvi SG, et al. Knowledge and perceptions of diabetes in a semi-urban Omani population. BMC Public Health. 2008; 8: 249. 